www.jmscr.igmpublication.org

Impact Factor 5.84

Index Copernicus Value: 71.58

ISSN (e)-2347-176x ISSN (p) 2455-0450

crossref DOI:_https://dx.doi.org/10.18535/jmscr/v6i1.14

Journal Of Medical Science And Clinical Research

IGM Publication

An Official Publication of IGM Publication

\title{
Review of Blood Transfusion Reactions in a Tertiary Hospital Blood Bank
}

\section{Dr Vanamala Alwar ${ }^{1}$, Dr Sitalakshmi $S^{2}$, Dr Shanthala Devi AM ${ }^{3}$, Dr Poornima Rao ${ }^{4}$ Dr Latha Fathima Shaju ${ }^{5}$, Dr Parimala Puttaiah ${ }^{6}$}

${ }^{1,3}$ Professor, Dept of Transfusion Medicine and Immunohematology, St John's Medical College Hospital

${ }^{2}$ Professor and Head, Dept of Transfusion Medicine and Immunohematology, St John's Medical College Hospital

${ }^{4}$ Ex - Lecturer, Dept of Transfusion Medicine and Immunohematology, St John's Medical College Hospital

${ }^{5}$ Assistant Professor, Dept of Transfusion Medicine and Immunohematology, St John's Medical College Hospital

${ }^{6}$ Lecturer, Dept of Transfusion Medicine and Immunohematology, St John's Medical College Hospital Corresponding Author

Dr Vanamala Alwar

Department of Transfusion Medicine and Immunohematology, St John's Medical College Hospital

Sarjapur Road, Bangalore560034

Email: vanamala.aa@stjohns.in, Mob-9480706112

\begin{abstract}
Background: Transfusion of blood components are vital therapeutic procedures in clinical medicine. However patients may still be at risk of adverse effects of transfusions. Analysis of all untoward effects of blood transfusion must be monitored in order to correct their cause and prevent recurrence. This study was designed to analyse the incidence and spectrum of adverse effects of blood transfusion so as to initiate measures to minimize risks and improve overall transfusion safety.

Methods: In the present study, we totally reviewed data over 12 years. All the acute transfusion reactions of blood components, that were reported to the hospital blood bank were included. Reactions due to Platelets and delayed transfusion reactions were excluded. The transfusion reaction workup done for these reported cases included; verification of patient identity and clinical records, examination of blood transfusion set and bag, ABO and Rh blood grouping, cross matching (pre \& post transfusion samples)and urine analysis.

Results: Of the total 293023 transfusions during the study period, $417(0.14 \%)$ acute transfusion reactions $(A T R)$ were reported. The commonest type of reaction noted were of the allergic type $($ ANHTR) $(n=303$; $72.6 \%)$, followed by febrile non hemolytic transfusion reactions(FNHTR)(n=104;24.9\%), 8 (1.9\%)hemolytic transfusion reactions(HTR). 2 cases of the NHTRs presented with clinical suspicion of TRALI. All the HTRs were due to packed red cell (PC) transfusions. 324 NHTRs were due to red cell transfusions, 85 due to infusion of plasma.

Conclusions: The NHTRs were far more in number (esp the ANHTRs), effective leucodepletion holds the key. HTRs were completely preventable but far more dangerous clinically. A strict protocol needs to be followed not only in the blood bank, but also in other relevant procedures like; pre transfusion sampling, storage outside blood banks, bed side patient identification and monitoring of transfusion to ensure blood safety and reduce such adverse effects
\end{abstract}

Keywords: Transfusion reactions, hemolytic, non-hemolytic. 


\section{Introduction}

With the discovery of the ABO blood groups by Karl Landsteiner, the fatalities and severe adverse effects of blood transfusion reduced drastically. ${ }^{1}$ Further advances including screening for the transfusion transmitted diseases were introduced in the mid 21 st century and advances in serology (including Coombs cross match) made transfusions safer. Unfortunately even, in today's age of modern medicine; transfusion related adverse effects are still recorded. The common reasons found in literature include alloimmunisation, Febrile, allergic reactions, volume overload, bacterial contamination and last but not the least reactions that result due to human errors. ${ }^{2}$

Acute transfusion reactions are one of the most important factors monitored as part of Hemovigilance programs towards patients receiving transfusions. Haemovigilance is a set of surveillance procedures covering the whole transfusion chain from the collection of blood and its components to the follow-up of its recipients intended to collect and assess information on unexpected or undesirable effects resulting from the therapeutic use of labile blood products and to prevent their occurrence and recurrence. It is an important tool for improving safe blood transfusion practices in a country. The Haemovigilance Programme of India (HvPI) was launched on 10th December, 2012 in the country by under the National Institute of Biologicals (Ministry of Health and family welfareGovernment of India) NIB in collaboration with the Indian Pharmacopoeia Commission (IPC). Currently, 154 centers have been enrolled in this program. $^{3}$

The need for safe blood transfusion was felt as early as 1980's and 1990's when many hemophilia patients in the developed countries contracted HCV and HIV from blood transfusions and factor concentrates. ${ }^{4}$ This dangerous example in history emphasized the need for hemovigilance. The work on hemovigilance was first initiated in France in 1991, with the setup of monitoring systems by Blood Transfusion Committees followed by the inception of Centre National d'Hemovigilance in 1992. ${ }^{5}$ Currently, on a global scale an International Hemovigilance Network (IHN) is functional, and an international database International Surveillance of Transfusion Associated Reactions and Events has been formed to share hemovigilance data across the globe. ${ }^{6}$

The information obtained through hemovigilance is imperative to make necessary changes in transfusion policies, for amendments in transfusion practices in hospitals and blood services, to enhance transfusion standards, to help in formulating transfusion guidelines and to improve quality and safety of entire transfusion process. As per the Ministry of Health and Family Welfare, Government of India, there are 2545 authorized blood banks in India which emphasise the need of a centralized hemovigilance system in India. $^{7}$

The scope of hemovigilance encompasses issues related to donors and blood collection, blood bank testing methods, documentation and finally patient related issues. As an initial attempt, the present study was undertaken in order to review the transfusion protocols followed in our hospital for any possible loopholes and to document all acute transfusion reactions.

\section{Aim}

1. To analyse the incidence and spectrum of adverse effects of blood transfusion and

2. To initiate measures to minimise risks and improve transfusion safety

\section{Materials and Methods}

All recorded acute transfusion reactions from 2004 to 2016 were reviewed and included in the study. Data from 2004 to 2012 were reviewed retrospectively. Post training period (2012 onwards upto 2016) data was recorded prospectively. Repeated training sessions were held from September 2012 onwards on regular basis to the nursing staff, doctors involved with blood transfusion and blood bank technical staff. 
The record of reactions reviewed included: (1) Verification of patient id, relevant clinical records, (2) Examination findings of the blood transfusion set and bag, (3) Record and review of $\mathrm{ABO}$ and $\mathrm{Rh}$ blood grouping of the blood unit, pre and post transfusion patient sample and pilot sample (collected from the donor during blood collection) (4) Analysis of Post transfusion urine sample of the patient

Reactions due to platelet transfusions and delayed transfusion reactions were excluded.

\section{Results}

Of the 293023 transfusions, in the period (20042016), 417 (0.14\%) of Acute transfusion reactions (ATR) were recorded.
Types of reactions: While 8 were Hemolytic transfusion reactions (HTRs), the majority were NHTRs $(n=409)$

NHTRs were Allergic (ANHTR, $\mathrm{n}=303$ ) and Febrile (FNHTR, $\mathrm{n}=104$ ) types.2 cases were clinically suspected to have TRALI.

All 8 HTRs were due to Red cell transfusions. While 278 (66.7\%) NHTRs were due Packed Red cell transfusions (PC), 46 (11.03\%) due to whole blood (WB) and 85 (20.9\%) were due to Plasma transfusions. (Fig1)

Fig 1: Types of Blood units transfused

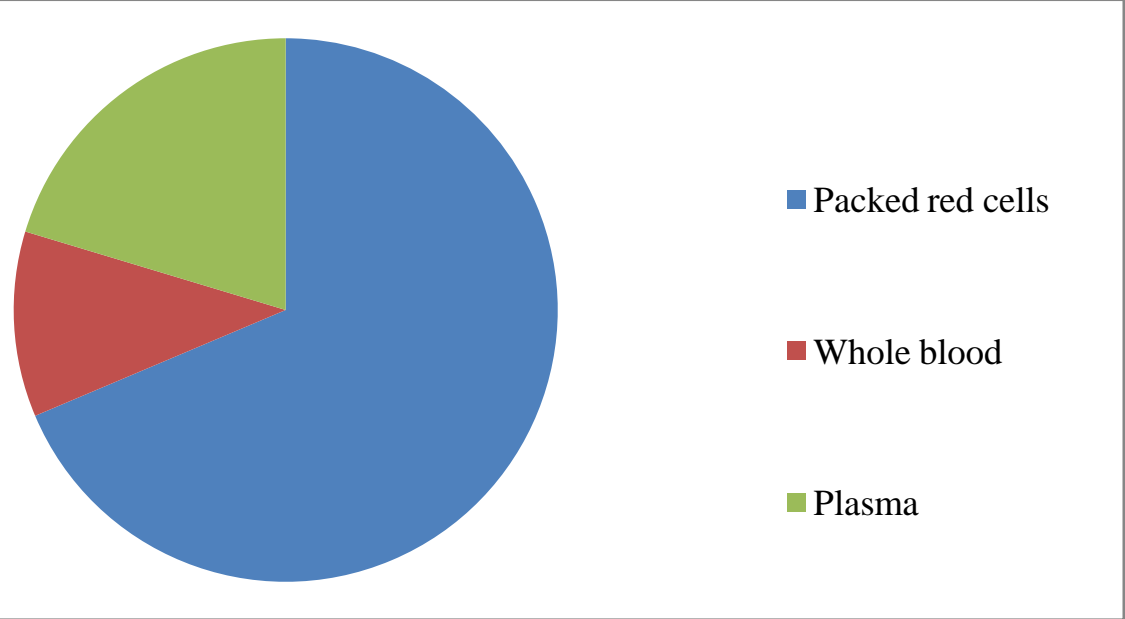

Correlating with prevalence of blood groups in our patient population, $\mathrm{O}$ blood groups were most commonly implicated (143, O Positive and 5, O Negative), followed by B group (142, B positive and 7, B Negative). The patients with Blood groups A (84, A Positive and 7, A Negative) and Group AB (28, AB Positive and 1, AB Negative) were fewer.

\section{a) Allergic NHTRs}

Allergic symptoms were classified into mild moderate and severe.

Mild: Rashes, sweating, burning sensation, periorbital edema, abdominal distension

Moderate: chest pain, restlessness, breathlessness, vomiting, giddiness
Severe (anaphylactoid): Respiratory distress, tachycardia, bradycardia, seizures, hypotension, Clinical Anaphylaxis

Of the the 303 ANHTRs, 225 were classified as mild, 48 as moderate and 27 as severe. 3 cases were diagnosed clinically as anaphylaxis.

\section{b) Febrile NHTRs}

104 cases of FNHTRs were noted with a recording of rise in temperature of $>1 \mathrm{deg}$ F/C. Rigors and chills were commonly associated in FNHTRs.

\section{c) HTRs}

The 8 cases of HTR were evaluated and the cause of hemolysis is summarized in Table 1. 
The most common cause was:

1. Inappropriate handling /storage after release of units from blood bank (4 cases). Use of spot light for warming blood quickly in the Neonatal ICU.

2. In 3 cases, 2 of which error were due to improper patient identification protocols being followed during collection of pre transfusion samples, sent to blood bank for cross matching. 1 was improper identification during release from blood bank

3. 1 case was due to transfusion of a G6 PD deficient donor unit to a baby

\section{Indications for transfusion were as specified in}

\section{Table 2}

The most common indication for red cell transfusions was severe anemia $(n=131$ out of 332 units transfused) and bleeding was the most common indication for Fresh frozen plasma transfusions ( $\mathrm{n}=25$ out of 85 units)
Steps taken: Post collection of the retrospective data upto 2012, repeated training sessions with nursing staff and resident doctors were held regarding; necessary protocols for patient identification(including use of wrist bands for inpatients with barcodes), procedure for pretransfusion sampling, protocols for transfusing blood components- including monitoring and reporting of transfusion reactions. Discussions at the transfusion committee meetings with senior doctors and Nursing incharges to reinforce the right methods esp in patient identification was emphasised.

\section{Comparison of data between retrospective and prospective periods of study (Table 3)}

From 2013 to 2016 December, no haemolytic transfusion reactions have been reported in the hospital, indicating the importance of strictly following the above mentioned protocols.

Table 1: Details of Hemolytic transfusion reactions

\begin{tabular}{|c|c|c|c|c|}
\hline $\begin{array}{l}\text { Patient's } \\
\text { group }\end{array}$ & ward & Transfusion & Workup results & Cause \\
\hline A Pos & NICU & A Pos $50 \mathrm{ml} \mathrm{PC}$ & $\begin{array}{l}\text { Hemolysis in bag and Post tx** } \\
\text { sample }\end{array}$ & Bag warmed in spot light \\
\hline B Pos & PICU & B Pos $125 \mathrm{ml}$ & $\begin{array}{l}\text { Bag sample and Post } \\
\text { tx**sample was hemolysed. } \\
\text { PreTx sample-Neg* }\end{array}$ & $\begin{array}{l}\text { Bag warmed in the spot } \\
\text { light before transfusion }\end{array}$ \\
\hline O Pos & NICU & O Pos $75 \mathrm{ml}$ & $\begin{array}{l}\text { Hemolysis in Post tx** sample } \\
\text { and urine. Bag-Neg* }\end{array}$ & G6PD deficient donor unit \\
\hline O Pos & MICU & O Pos $200 \mathrm{ml}$ & Hemolysis in the bag & 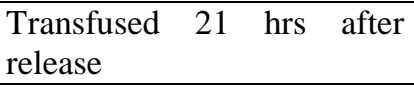 \\
\hline O Pos & Pvt ward & $\begin{array}{l}\text { AB Pos } 20 \mathrm{ml} \\
\text { Pretransfusion sample) }\end{array}$ & $\begin{array}{l}\text { Mild Hemolysis in post tx** } \\
\text { sample }\end{array}$ & $\begin{array}{l}\text { Pre Sample sent from } \\
\text { another patient for cross } \\
\text { match }\end{array}$ \\
\hline O Pos & FMITU & $\begin{array}{l}\text { Given B Pos blood } \\
\text { crossmatched for another } \\
\text { patient with same name } \\
\end{array}$ & $\begin{array}{l}\text { Mild Hemolysis in post tx** } \\
\text { sample }\end{array}$ & $\begin{array}{l}\text { Error in blood released from } \\
\text { blood bank }\end{array}$ \\
\hline O NEG & Pvt wd & $\begin{array}{l}\text { B } \quad \text { pos } 15 \quad \text { ml } \\
\text { ( Pretransfusion sample) }\end{array}$ & No hemolysis & $\begin{array}{l}\text { Pre Sample from another } \\
\text { patient }\end{array}$ \\
\hline O Pos & $\begin{array}{l}\text { Outside } \\
\text { nursing home } \\
\text { With PPH }\end{array}$ & Complete unit transfused & Hemolysis in post tx**sample & $\begin{array}{l}\text { Bag stored for } 1 \text { day post } \\
\text { release in the freezer } \\
\text { compartment }\end{array}$ \\
\hline
\end{tabular}

*Neg- No hemolysis, **tx-transfusion 
Table 2: Indications for Transfusions

\begin{tabular}{|l|c|}
\hline Red Cells- indications & Total- 332 \\
\hline Severe anemia & 80 \\
\hline Moderate anemia & 51 \\
\hline CKD & 32 \\
\hline $\begin{array}{l}\text { Surgery } \\
\text { correction of anemia) }\end{array}$ & 80 \\
\hline Infections & 14 \\
\hline Bleeding & 19 \\
\hline Thalassemia & 21 \\
\hline Malignancies & 35 \\
\hline Plasma indications & Total- 85 \\
\hline Hemophilia & 14 \\
\hline Bleeding & 25 \\
\hline Surgery & 17 \\
\hline Liver disease & 13 \\
\hline GBS & 3 \\
\hline Nephrotic syndrome & 9 \\
\hline vWD & 4 \\
\hline
\end{tabular}

Table 3: Comparison of data between retrospective and prospective periods of study

\begin{tabular}{|l|c|c|}
\hline Type of reaction & $2004-2012$ & $2013-2016$ \\
\hline NHTR & 407 & 105 \\
\hline HTR & 8 & nil \\
\hline
\end{tabular}

\section{Discussion}

The overall reported rates of Acute Transfusion Reactions (ATR) range from $0.2 \%$ to $10 \%$. $^{2,8,9,10}$ In the present study, a reaction rate of $0.19 \%$ was noted, excluding platelet transfusions.

In addition, transfusion of red cells were the most common cause of ATRs in most studies. ${ }^{11,12}$ This was ratified in the present study where $79.6 \%$ of the reactions were due to red cell transfusions.

\section{Types of reactions}

\section{a. Hemolytic Transfusion reactions:}

The reported overall risks for acute HTR observed in different studies range from $0.02-0.07 \%$ to 3 $5 \%$ per 1000 red cell unit transfusions. ${ }^{8,9,10}$

In the Indian study by Bhattacharya et al, the reported rate was $0.23 / 1000$ red cell units. The present study we observed a rate of $0.05 / 1000$ red cell units ( 8 cases for 151888 transfusions)

The causes of HTRs have been classified as immune and non immune.

Immune causes include $\mathrm{ABO}$ and more commonly non ABO incompatibility eg Anti M, Anti P, Anti $\mathrm{C}$, Anti $\mathrm{K}$ etc, as has been reported in various. ${ }^{11,12}$
Surprisingly in the present study, all the cases were attributed to non immune causes, such as errors in Patient identification (including, both in the blood bank and Bed side), sample errors, storage errors, and after release from blood bank storage and transport errors etc.

The other study by Bhattacharya et al also attributed 7 out of the 9 cases of HTRs to non immune causes.

It must be emphasised, to prevent these life threatening situations strict protocols must be put in place for:

1) Patient identification at the bed side. Use of bar coded wrist bands with complete patient identification has been introduced in major centres.

2) Following uniform protocols regarding handling and storage of blood products, with repeated educational reinforcement to all the concerned hospital and technical staff.

3) Monitoring blood product transfusions and prompt reporting of any untoward incidents to blood bank immediately.

\section{b. Febrile Non haemolytic transfusion reactions}

FNHTRs are defined as a transfusion reactions, observed as increase in body temperature of $>1$ degree $\mathrm{C}$ or greater unrelated to sepsis, hemolysis or other known causes of fever, that can occur during or within several hours of transfusion. ${ }^{9}$

Pathophysiology: FNHTRs appear due to 3 possible underlying causes:

a) Infusion of passenger leucocytes into recipients alloimmunised against leucocytes or platelets ${ }^{14,15}$

b) Infusion of pyrogenic cytokines/mediators (eg IL-6, IL1 -B, aTNF alpha) that accumulate in plasma portion of the component during storage. 16-18

c) Infusion of components contaminated with bacteria/bacterial products. ${ }^{19}$

d) Effective leucoreduction (esp prestorage leucoreduction) is an effective way to prevent FNHTRs. 
The reported rate of FNHTR varies from 0.5 to 1 $\%{ }^{20}$

A comparative study on incidence of FNHTR in leucoreduced vs non leucoreduced blood components showed that the incidence was higher $(0.12 \%)$ in the former group compared to the latter $(0.08 \%)$ which used pre storage leucoreduced blood. $^{21}$

In other studies the rates of FNHTRs are 0.55 for red cell transfusions and $0.3-3 \%$ for platelets on non leucoreduced units, and $0.08-0.5 \%$ for red cells and $0.03-0.12 \%$ for platelets in leucoreduced units. ${ }^{22}$

Our centres used buffy coat removal technique in component preparation, reducing the leucocyte load in packed red cells. In the our study FNHTR was seen for Packed red cells at the rate of $0.04 \%$ (59/149595 transfusions) -and for Whole Blood transfusions at the rate of $0.25 \%(45 / 17585$ units). Whole blood units showed higher rates than the red cell concentrates.

The other relevant debate found in literature was, whether pre medication with anti pyretics can be made routine for prevention of FNHTRs. $^{23}$ Though it is argued as an advantageous practice, one must wonder whether, the premedication may mask more severe signs of anaphylaxis, TRALI etc.

\section{c. Allergic Non Hemolytic transfusion reactions}

These reactions are type I hypersensitivity reaction in response to the proteins in the donor plasma22. Most studies quote an incidence of mild allergic reactions in 0.2 to $3 \%$ of transfusions. ${ }^{2,10,24}$

In the present study ANHTR was seen in $1.99 / 1000$ units.

Severe anaphylactoid reactions characterized by respiratory distress, tachycardia or bradycardia, seizures and hypotension may be observed.

The rates for such reactions vary from 0.00212,24 in developed countries to 0.2 to $1.02 / 1000$ units in developing Asian countries. ${ }^{11}$
In the present study 3 cases with anaphylactoid reactions were noted.

Hypotension is an important sign indicating a transfusion reaction as was noted first by Domen et al. ${ }^{25}$

It was seen commonly in the study by Bhattacharya et al (50\%) ${ }^{12}$ and the present study (36\%).

Respiratory distress was another common finding and seen by Bhattacharya et al (50\%) and the present study (16\%) cases. The present study on Acute transfusion reactions had a few lacunae, as evaluation for certain other conditions like Hypovolemia, Hypocalcemia, bacterial culture for sepsis or proven cases of TRALI were not evaluated for.

On review of clinical data retrospectively, 1 patient had complained of breathlessness after transfusion, in a male general medical ward. He was kept under observation for 2 days as his oxygen saturation was $<95 \%$ during that period. He was treated symptomatically and subsequently his condition improved. Retrospectively, we suspect this could have been a case of TRALI.

After the launch of the national hemovigilance program, about 765 adverse reports were submitted via hemovigil software by centers to NIB. Of 735 reports submitted between February to November 2013, $364(49.7 \%)$ were febrile nonhemolytic transfusion reactions and 167 (22.8\%) were allergic reactions. Of the reactions reported under the Hemovigilance Program of India, Not a single case of transfusion-related acute lung injury were reported which may be a result of under-diagnosis as well as underreporting. $^{26}$

Despite being active, there is overall underreporting of adverse reactions associated with blood transfusion. WHO identified that the fragmented blood transfusion systems, lack of government commitment, lack of understanding among clinicians, lack of culture of reporting, fear of punishment, lack of expertise and regulatory framework on hemovigilance, lack of computerized management system might be 
challenges for the implementation of hemovigilance program in the world. ${ }^{27}$ Awareness among treating staff to pick up these important clinical signs and reporting it to the hemovigilance cell/blood bank must be reinforced. Proper monitoring of transfusions reporting of all such reactions will be a prerequisite for accurate calculation of ATR incidence.

\section{Conclusions}

1) Patients undergoing transfusions have to be monitored closely for any occurance of ATRs, especially the dangerous signs of HTRs.

2) Increased awareness of treating staff and repeated reinforcement programs regarding:

(i) patient identification protocols during sampling and before transfusions (ii) handling of blood components before and during transfusions(iii) monitoring of patients during and post transfusion(iv) reporting of transfusion reactions

In our experience, these interactions brought down the HTRs to nil in the past 4 years.

3) Though NHTRs are far more frequent they can be prevented effectively by measures like leucoreduction

4) The HTRs, though fewer are life threatening and therefore steps must be taken to avoid these easily preventable clinical disasters.

\section{References}

1. Aubuchnon JP, Kruskall MS. Transfusions safety: Realigning efforts with risks. Transfusion 1997;37:1211-6

2. Kleinmman S. Chan P Robillard P. Risk associated with transfusion of cellular blood components in Canada. Transfus Med Rev. 2003:17120-62

3. National Institute of Biologicals, Ministry of Health and Family Welfare, Government of India. [updated 2016 June 3; cited Dec 2012]. Haemovigilance Programme of India.National Institute of Biologicals \& India Pharmacopoeia
Commission Collaboration. (about 1 screen)

Available

from: http://www.nib.gov.in/haemovigilan ce1.html.

4. Tutu EK. A review of international blood safety and quality regulations: Key implications for blood organizations and hospital blood transfusion practice. Can $\mathrm{J}$ Med Lab Sci 2011;73:6-12.

5. Salmi R. Epidemiological support of hemovigilance. Transfus Clin Biol 1994;6:421-4.

6. Jain A, Kaur R. Hemovigilance and blood safety. Asian J Transfus Sci 2012;6:137-8

7. Robillard P, Nawej KI, Jochem K.The Quebec haemovigilance system: descryption and results from the first two years. Transfus Apher Sci. 2004;31:111-22.

8. Moore S, Taswell HF, Pineda AA. Delayed hemolytic transfusion reactions: Evidence of the need for an improved pretransfusion compatibility test. Am J Clin Path 1980;74:94-7.

9. Lichtiger B, Thornton E. Hemolytic transfusion reactions in oncology patients: Experience in a large cancer center. J Clin Oncol 1984;2:438-42.

10. Khalid S, Usman M, Khurshid M. Acute transfusion reactions encountered in patients at a tertiary care center. J Pak Med Assoc. 2010;10:832-36

11. Bhattacharya P, Marwaha N, Dhawan HK, Roy $\mathrm{P}$ and Sharma RR. Transfusionrelated adverse events at the tertiary care center in North India: An institutional hemovigilance effort. Asian Journal of Transfusion science 2011;5:164-170

12. Febrile, Allergic and Non immune Transfusion reactions. Stack G,Pomper GJ. In: (eds) Simon TL, Dzik WH, Snyder EL et al; Rossi's Principles of Transfusion Medicine: 3rd edition .Philadelphia: Lippincott Williams and Wilkin;2002:831851 
13. die Rie MA, van der Plas-van Dalen CM, Engelfriet $\mathrm{CP}$, van dem Borne AEGKr . The serology of febrile transfusion reactions. Vox sang 1985;49: 126-134

14. Brubaker DB. Clinical significance of white cell antibodies in febrile non hemolytic transfusion reactions. Transfusion 1990;30:733-37

15. StackG, Snyder EL. Cytokine generation in stored platelet concentrates. Transfusion 1994;34:20-25

16. Muyelle L, Joos M, Wouters E et al. Increased tumour necrosis factor, interleukin 1 and interleukin 6 levels in platelet concentrates: Relationship between TNF and IL-6 levels and febrile transfusion reactions. Transfusion 1993;33:195-99

17. Heddle NM, Klama L, Singer J, Richards C, Fedak P, Walker I, Kelton JG. The role of plasma from platelet concentrates in transfusion reactions. $\mathrm{N}$ Eng $\mathrm{J}$ Med . 1994;331: 625-28

18. Sharma AD, Grocott HP. Platelet transfusion reactions:febrile non hemolytic reaction or bacterial contamination? Diagnosis, detection and current preventive modalities. J Cardiothorac vasc Anesth.2000;14: 460-66

19. NIH consensus conference: Perioperative red cell transfusion. JAMA 1988;260: 2700-3

20. Ulhman EJ, Isgrigs E, Wallhermanfechtel M, Goodnough LT. Prestorage universal WBC reduction of RBC units does not affect the incidence of transfusion reactions. Transfusion 2001;41:997-1000

21. Tyler VV, Benson K, Branch DR, Loni Calhoun MT, Dzik WH, Leparc GF et al. editors. Non infectious Complications of Blood transfusion. In; Technical manual of the American Association of Blood Banks. 12th Ed, Bethesda ,Maryland.1996 : 543-61

22. Ezidiegwu, CN, Lauenstein KJ, Rosales LG, Kelly KC, Henry JB. Febrile
Nonhemolytic Transfusion Reactions Management by Premedication and Cost Implications in Adult Patients. Arch Pathol lab med 2004;128:991-95

23. Tanz WS, King KE, Ness PM. Reevaluation of transfusion reaction rates associated with leukocyte-reduced red blood cells. Transfusion 2001;41:7s (abstr suppl).

24. Domen RE, Heoltage GA, Allergic transfusion reactions. Arch Path Lab Med 2003; 127:316-20

25. Marwaha N, Singh S, Bisht A. ISBT Science Series. Vol. 9. Hoboken, NJ: Wiley Publishers. 2014. p. 178-83

26. Global Consultation on Haemovigilance. 20-22 November 2012, Dubai, United Arab Emirates. Jointly Organized by WHO HQ/Geneva, Sharjah Blood Transfusion and Research Center and the Government of the United Arab Emirates, in Collaboration with the International Haemovigilance Network and the International Society of Blood Transfusion. 2012. [cited 2013].Available from: http://www.who.int/bloodsafety/hae movigilance/haemovigilance-report.pdf. 